\title{
A CATEGORIA DE GÊNERO E O SEU ESTATUTO NA PRODUÇÃO DO CONHECIMENTO: ALGUMAS CONSIDERAÇÕES TEÓRICAS
}

\author{
THE GENDER CATEGORY AND ITS STATUTE IN KNOWLEDGE \\ PRODUCTION: SOME THEORETIC CONSIDERATIONS
}

\author{
NeIVA FuRLIN ${ }^{1}$
}

Recebido em: 27/01/2014 Aprovado em: 01/10/2014

\section{RESUMO}

Considerando a relevância do conceito de gênero na produção do conhecimento e na compreensão dos comportamentos sociais, o presente ensaio busca descrever o processo de sua emergência e de sua construção e alguns de seus desdobramentos na trajetória dos estudos feministas, com destaque para a perspectiva pós-estruturalista, por ser a mais recorrente no conjunto dos estudos de gênero nesses últimos anos. Trata-se de um ensaio teórico-reflexivo que visa mostrar o estatuto desse conceito nos processos do conhecimento e a sua importância para as Ciências Sociais, disciplina que tem como problemática central a compreensão das relações sociais. Além de seu estatuto analítico, o conceito de gênero constitui uma proposta metodológica. Portanto, a maior valorização desse instrumental teórico nos processos de produção do conhecimento crítico caracterizase, hoje, como um dos aspectos que possibilita a construção de uma sociedade mais justa, igualitária e equitativa.

Palavras-chave: Conceito de gênero; Pós-estruturalismo; Conhecimento; Ciências Sociais.

\begin{abstract}
Considering the relevance of the gender concept in the production of knowledge and comprehension of social behavior, this article seeks to describe the process of its emergence and construction, as well as some of its developments in the trajectory of feminist studies, with stress on the poststructuralist perspective, because of its recurrent use in the general field of gender studies in recent years. The theoretic-reflexive tenor aims to show the statute of this concept in knowledge processes and its significance for social sciences whose central object is the comprehension of social relationships. Beyond its analytical statute, the gender concept constitutes itself as a methodological proposal. Today, an increased valorization of this theoretic instrument in processes of critical knowledge production is therefore one of the aspects that enable to construct a more just, egalitarian and equitable society.
\end{abstract}

Keywords: Gender Concept; Poststructuralism; Knowledge; Social Sciences. 


\section{Introdução}

A emergência dos estudos de gênero introduziu novas abordagens teóricas em diversas áreas do conhecimento humano. Esses estudos se contrapuseram às perspectivas universalizantes da ciência e mostraram que, nas diferentes sociedades humanas, as relações sociais vividas entre homens e mulheres são construídas a partir da tradição cultural de cada região e das especificidades de cada momento histórico. Tais diferenças são evidentes dentro de uma mesma sociedade, em seus diferentes grupos sociais, e se modificam ao longo da história devido à dinamicidade da própria cultura; situação que também atinge a divisão sexual de trabalho nas diversas instituições.

Os estudos feministas têm argumentado que o gênero exerce influência no conhecimento, seja no sujeito que o produz, seja nas práticas de investigação, indagação e justificação. Nesse sentido, uma de suas principais contribuições foi justamente apontar que o sujeito do conhecimento tem gênero e está situado em um contexto social concreto. Isso implica considerar que nenhum conhecimento é puramente objetivo, porque é marcado por aspectos da subjetividade de quem o produz.

Tendo em vista a importância que a categoria de gênero adquiriu ao longo dos últimos 40 anos na academia e fora dela, por permitir compreender como as dinâmicas e práticas socioculturais produzem desigualdades entre mulheres e homens, este ensaio tem por objetivo evidenciar a emergência da categoria de gênero, sua trajetória e os desdobramentos teóricos no interior dos estudos feministas, dando destaque à perspectiva pós-estruturalista por ser a mais utilizada nos estudos atuais. Também se objetiva expor alguns aspectos sobre a importância da categoria de gênero nos processos de produção acadêmica, já que ela é uma ferramenta de grande valor na compreensão das relações de dominação e de desigualdades sociais entre os diferentes gêneros.

\section{$2 O$ conceito de gênero: trajetória e desdobramentos teóricos}

O gênero aparece como uma das categorias analíticas produzida pela teoria feminista contemporânea e assumida pelas diferentes áreas acadêmicas para a compreensão dos comportamentos sociais entre homens e mulheres. Esse conceito nasceu no interior do movimento feminista norte-americano e de sua articulação com a academia, opondo-se à dominação e à opressão masculina. Tal movimento, além de ganhar expressividade política, voltou-se para a produção teórica, dando início, assim, à problematização em torno do conceito de gênero ${ }^{2}$.

Será no desdobramento da assim chamada 'segunda onda' - àquela que se inicia no final da década de 1960 - que o feminismo, além das preocupações sociais e políticas, irá se voltar para as construções propriamente teóricas. No âmbito desse debate crítico que, a partir de então, se trava entre estudiosas e militantes será engendrado o conceito de gênero (LOURO, 1999, p. 15).

Embora o conceito de gênero tenha sido sistematizado pelo debate feminista contemporâneo, as suas raízes têm sido atribuídas à afirmação de Simone de Beauvoir (1949) de que "não se nasce mulher, se torna mulher", por meio da qual ela problematizava as relações entre sexo biológico e construção da categoria social de mulher. As teóricas contemporâneas partiram desse pressuposto para elaborar o conceito de gênero, colocando em cena o caráter sociocultural das distinções que, até então, eram concebidas como determinadas pelo sexo biológico. Ao insistir no argumento da construção social de

Entretanto, na genealogia sobre o termo "gênero", elaborada por Gabriela Castellanos Llanos (2006), constata-se que esse termo já havia sido utilizado com outros sentidos desde o século XVII 
gênero, elas rejeitavam o determinismo biológico. Nesse sentido, a sistematização de gênero como categoria analítica ocorreu durante os anos de 1970 e, aos poucos, passou a ser objeto de discussão e de análise na produção acadêmica das ciências humanas e sociais.

Nos anos de 1960 e 1970, os estudos de gênero focaram-se em torno da oposição sexo/gênero e natureza/ cultura, como uma forma de explicar a situação de opressão e subordinação das mulheres, no sistema do patriarcado, que se fundava na ideia da essencialização do feminino e do masculino, como categorias binárias e universais. $\mathrm{O}$ modelo do patriarcalismo, mesmo sem haver um consenso entre as feministas, permitiu olhar a problemática da opressão das mulheres a partir de uma visão mais ampla, incentivando a organização das mulheres na luta por autonomia e na superação dos papéis de subordinação e dependência. Esses estudos questionaram não apenas a posição de subordinação das mulheres, mas também as ideologias que mantinham a reprodução dos papéis sexuais. Com a tomada de consciência sobre o papel imposto por uma cultura patriarcal, as mulheres denunciaram a estrutura patriarcal presente nas dinâmicas sociais e institucionais, assumindo bandeiras de luta por autonomia e igualdade de gênero em todos os níveis da sociedade.

Um texto pioneiro que veio contribuir com essa discussão foi o da antropóloga Gayle Rubin (1993)3 , que apresenta uma das primeiras explicações contemporâneas para o gênero, ao definir o "sistema de sexo/gênero" como "um conjunto de arranjos através dos quais uma sociedade transforma a sexualidade biológica em produto da atividade humana e, nos quais as necessidades sexuais são satisfeitas" (RUBIN, 1993, p. 2). Com essa definição, a antropóloga pretendia nomear os aspectos políticos, econômicos e sociais do sistema "sexo/gênero", que permitia ${ }_{3}^{3}$ Seu artigo "O tráfico das mulheres" tem tido destaque na literatura sobre a segunda fase da elaboração do conceito de gênero. compreender a opressão das mulheres. Por meio do sistema sexo-gênero, Rubin reconhece a construção social do gênero como uma construção social da dominação (MACHADO, 1998). Entretanto, nesse sistema, a dimensão biológica continuou sendo assumida como a base sobre a qual os significados culturais eram construídos.

Patrícia Soley-Beltran (2009) reconhece que, inicialmente, a distinção sexo/gênero foi utilizada por teóricas feministas para centrar-se na variabilidade cultural e histórica do gênero, com o fim de argumentar contra o essencialismo na definição da identidade de gênero e do determinismo biológico dos papéis sociais para o universo masculino e feminino. Essa primeira distinção, construída nos anos de 1980, passou a ser criticada por conservar a noção da construção do gênero vinculada ao determinismo biológico. Nesse primeiro momento do feminismo contemporâneo, o conceito de gênero foi compreendido, praticamente, como substituto de "sexo", de modo que a diferença de gênero correspondia à diferença sexual. Conforme a crítica de Lauretis (1994), essa maneira de compreender o gênero limitou o pensamento feminista, por não questionar a oposição binária entre mulheres e homens e por manter essas categorias como dicotômicas. Nessa mesma direção, Nicholson (2000, p. 10) aponta que a categoria de gênero, construída no contexto das abordagens estruturalistas, manteve-se durante muito tempo dentro de parâmetros binários, segundo os quais o sexo correspondia ao campo da natureza e o gênero ao da cultura. Assim, em uma espécie de metáfora, o corpo seria um cabide sobre o qual era possível colocar diferentes artefatos culturais, sobretudo os relacionados com o comportamento e a personalidade. Essa relação entre corpo, personalidade e comportamento é nomeada por Nicholson de "fundacionismo biológico", no intuito de diferenciá-lo do determinismo biológico. Sua 
concepção é de que, "em contraste com o determinismo biológico, o fundacionismo biológico permite que os dados da biologia coexistam com aspectos de personalidade e de comportamento" (NICHOLSON, 2000, p. 13).

Além das críticas ao sistema binário de gênero fundado no determinismo biológico, ainda nos anos de 1980, os estudos feministas começaram a abordar a problemática da diferença como uma questão contextual, relacional e histórica, incluindo, nesse debate, as diferenças existentes em um mesmo gênero que poderiam ser evidenciadas pelo recorte de raça, classe e etnia. Nessa década, um dos debates das feministas, amplamente conhecido, foi o da "igualdade versus diferença", considerado um avanço nas bandeiras de luta que tematizavam a diferença ${ }^{4}$. De um lado estavam as feministas clássicas que defendiam a estratégia da igualdade, como uma forma de garantir a luta por emancipação social e a igualdade de direitos, em relação ao sexo masculino. Opondo-se a essas feministas, conhecidas como da igualdade ou do feminismo liberal, as partidárias da estratégia da diferença, ou do feminismo cultural defendiam que a luta das mulheres só podia ser empreendida levando-se em conta os interesses e as características comuns das mulheres como pertencentes a um grupo social e cultural específico ${ }^{5}$.

Nesse contexto, os estudos da historiadora Joan Scott problematizam os debates que polarizam igualdade e diferença.

Os termos que defendiam a inclusão das mulheres na política envolviam o esforço da busca por uma definição abalizada de gênero fez com que as feministas se defrontassem com um dilema sem saída. Esse dilema chegou até nós na forma de debates sobre "igualdade" ou "diferença": serão

${ }^{4}$ Segundo o sociólogo Antônio Pierruci (1990), foi nesse tempo que se começou a falar em "diferença cultural", "cultura feminina", "cultura das mulheres", "experiência feminina" e, "reconhecimento da diversidade cultural de gênero".

${ }^{5}$ Uma discussão mais aprofundada sobre essas questões pode ser encontrada no livro Las voces de la experiencia: el viraje de la filosofía feminista, de Ana María Bach, 2010. as mulheres iguais aos homens, fato do qual decorreria a única base para se reivindicar direitos? Ou serão seres diferentes e, por causa ou apesar das diferenças, com direito igual de tratamento? Qualquer das duas posições atribui identidades fixas e análogas aos homens e mulheres, ambas endossam implicitamente a premissa de que pode haver uma definição oficial e autoritária de diferença sexual. (SCOTT, 2002, p. 18).

Scott indica a necessidade da desconstrução de algumas ideias que se colocam acerca da cidadania universal. Ela argumenta ser necessário pensar em termos de pluralidade e diversidades ao invés de sujeitos universais e, construir teorias que rompam com os esquemas binários das tradições filosóficas ocidentais. As oposições binárias são hierárquicas, e se constroem por meio da oposição entre um termo dominante e um subordinado. A questão da igualdade versus diferença também tem sido colocada dentro dessas dicotomias. Para Scott, uma forma de enfrentar o "dilema da diferença" é desconstruir a disjunção que foi criada entre igualdade e diferença, mostrando que a "própria antítese esconde a interdependência dos dois termos já que a igualdade não é eliminação da diferença, e a diferença não exclui a igualdade" (SCOTT, 1999, p. 209). Com isso, a autora se contrapõe à ideia de que é preciso fazer uma escolha entre a diferença e a igualdade, considerando que os termos não constroem uma oposição, uma vez que o dilema da diferença é um "falso dilema". Por outro lado, a autora lembra que, na ação política, tais termos devem ter estratégias definidas em cada contexto discursivo particular, já que em certas situações as diferenças se constroem como relações de subordinação e que, portanto, precisam ser questionadas politicamente. Aqui, merece destaque a posição de Boaventura de Souza Santos (2000), quando propõe o princípio segundo o qual as pessoas e os grupos sociais têm 
o direito de ser iguais quando a diferença os inferioriza, e o direito de ser diferentes quando a igualdade os descaracteriza. $\mathrm{O}$ argumento de Boaventura Santos também aponta o "dilema da diferença" como um falso "dilema".

Pelas razões assinaladas por Scott, parece útil a nomenclatura de Nancy Fraser (1997), que, ao invés de feminismo da igualdade e feminismo da diferença, sugere os termos exigências de redistribuição e exigências de reconhecimento. $\mathrm{O}$ primeiro termo remete às injustiças distributivas, como o salário diferencial, o desempenho feminino, a feminização da pobreza e, em última instância, a mesma divisão sexual do trabalho. $\mathrm{O}$ segundo termo remete à dominação cultural, à invisibilidade e ao não respeito, incluindo fenômenos como o desconhecimento da liderança feminina, a banalização, a degradação e a exploração da sexualidade feminina, no uso de estereótipos sexistas contra as mulheres. Segundo Llanos (2006), essas posições continuam vigentes, já que ainda hoje se necessita tanto de reivindicações de igualdade de oportunidades ou de justiça redistributiva quanto de um reconhecimento e de uma valorização positiva das diferenças (dentre as quais está a de gênero).

Nesse sentido, é válida a proposta de Scott (1999) de que, por meio da desconstrução da antítese igualdade versus diferença, pode-se dizer que os seres humanos nascem "iguais, mas diferentes" e sustentar a ideia de que a "igualdade reside na diferença". Para essa autora, quando se pensa a partir da oposição macho/fêmea, acaba-se por obscurecer as diferenças que existem entre as mulheres, sejam elas de classe, de raça ou de comportamento, incluindo aspectos como subjetividade, sexualidade e identidade de gênero. Assim, ao problematizar a diferença, como uma questão contextual, relacional e histórica, que precisa ser levada em conta nas lutas políticas por igualdade social entre os gêneros, problematizaram-se tam- bém as diferenças existentes no interior de um mesmo gênero e a necessidade de incorporar as questões de raça, classe e etnia na discussão.

A compreensão de que o masculino e o feminino são construções sociais trouxe o consenso de que não existe o homem e a mulher como categoria universal, ou então uma essência masculina e feminina determinada e fixa, uma vez que o ser homem e o ser mulher é uma construção cultural, dinâmica, contextual, histórica e relacional. Além de assumir o caráter social do feminino e do masculino, foi necessário levar em consideração que a construção de gênero é distinta em cada sociedade e em cada momento histórico. Isso levou à compreensão de que "as questões de gênero são diferentes não apenas entre as sociedades, ou em distintos momentos históricos, mas também no interior de uma dada sociedade, ao se considerar os diversos grupos que a constituem" (LOURO, 1999, p. 23). Tais questões evidenciam que o gênero, tanto como categoria analítica quanto como processo social, é relacional, de modo que o conteúdo real do ser homem ou mulher e a rigidez das próprias categorias são altamente variáveis de acordo com as diferentes épocas e culturas (FLAX, 1992).

Uma das marcas significativas dos estudos de gênero nos anos de 1980 foi a incorporação da dimensão do poder do discurso e das representações culturais na construção do gênero. Essa novidade aparece conectada com as discussões filosóficas do pós-estruturalismo, que se funda na linguagem e nas ideias de construção e desconstrução, colocando em cena as dinâmicas microssociais de poder, conforme exposto no item seguinte.

\section{A abordagem de gênero na perspec- tiva pós-estruturalista}

No Brasil, Guacira Louro (1999) encontra-se entre as feministas que adotaram a perspectiva pós-estruturalista de 
gênero. Seus primeiros estudos sobre gênero e educação são inspirados na teoria de Joan Scott e de Michel Foucault. Para Louro, ao aceitarmos que a construção de gênero é histórica, entendemos que as relações entre homens e mulheres, assim como os discursos e as representações dessas relações, estão em constantes mudanças, o que supõe que as identidades de gênero estão sempre se constituindo, são instáveis e, portanto, passíveis de transformação, em contextos de mudanças culturais e em momentos históricos distintos. Essa mesma perspectiva pós -estruturalista se verifica em Teresa de Lauretis (1994), já que na sua visão "a construção de gênero também se realiza por meio da desconstrução" que, neste caso, remete à desconstrução dos significados culturais que foram construídos por uma leitura biológica do sexo.

Nesse contexto, as relações de gênero também foram compreendidas como relações de poder. Para Jane Flax, as relações de gênero têm sido relações de dominação, "e foram definidas e controladas por um de seus aspectos inter-relacionados - o homem" (FLAX, 1992, p. 228). Assim, o gênero aparece como uma relação social constituinte e, também, como uma relação de poder, em se ordenam e se compreendem os fatos socioculturais da existência humana.

A dimensão do poder é aprofundada a partir da definição de Scott (1990), que evidencia a existência de uma conexão entre gênero e poder. Para ela, o núcleo essencial do conceito de gênero encontra-se na relação entre duas proposições: "o gênero é um elemento constitutivo das relações sociais baseado nas diferenças percebidas entre os sexos, e o gênero é uma forma primeira de significar as relações de poder" (SCOTT, 1990, p. 14), isto é, o lugar primário no qual se articula o poder. O conceito de Scott ganhou importância nos estudos de gênero por inovar as concepções teóricas existentes na época e, sobretudo, por introduzir a dimensão histórica, a dimensão do poder relacional e a transversalidade de gênero como elemento cultural ${ }^{6}$. A sua noção de gênero inclui quatro elementos que operam simultaneamente, mas, para fim de análise, a autora considera ser necessário distingui-los: a) os símbolos culturalmente disponíveis que evocam representações simbólicas; b) os conceitos normativos que evidenciam as interpretações do sentido dos símbolos; c) a noção de política com referência às instituições e à organização social, que permite desvendar a natureza dos discursos ou a repressão que produz a permanência de uma representação binária de gênero; e d) a identidade subjetiva. Assim, para Scott (1990, p. 15), é importante que o pesquisador examine como as identidades de gênero são construídas, relacionando as descobertas com as formas de organização e as representações sociais situadas. Esses elementos são importantes para desvendar os processos que podem tanto manter como alterar a atual hierarquia entre os gêneros.

Para dar consistência à segunda proposição do seu conceito, em que o gênero é tido como um primeiro campo no interior do qual o poder é articulado, Scott baseia-se na teoria foucaultiana do poder, conforme a qual o poder não aparece situado ou fixo em estruturas estatais ou jurídicas, mas circula nas malhas das relações humanas e, por isso, é disseminado nas estruturas sociais, funcionando e sendo exercido em rede, em todas as direções, inclusive de baixo para cima. Nas malhas dessa rede, os indivíduos não só circulam, mas também estão em posição de exercer o poder e de sofrer sua ação. Foucault (1999a) não está preocupado em definir o que é o poder, mas em analisar como funciona e quais são os seus efeitos, já que ele atravessa os discursos, os saberes, as normas e as práticas sociais e, antes ser repressivo, apresenta-se como generativo e produtivo. Trata-se

\footnotetext{
${ }^{6}$ De acordo com Llano (2006), a partir da definição de Scott começou-se a considerar que a categoria de gênero tinha o mesmo estatuto social da categoria de classe, etnia/raça, já que esses aspectos estão presentes en todas as relações sociais e se interseccionam mutuamente. Além disso, a sua definição considera a dimensão política ao afirmar que o gênero é a
} forma primeira pela qual aprendemos as relações de poder. 
de um poder que é criador de significados, de valores, de saberes, de práticas e de subjetividades. $\mathrm{O}$ aporte teórico de Foucault tem sido significativo e inspirador para os estudos feministas, por permitir analisar o fenômeno do poder também no nível microssocial, que é onde se inscrevem as relações sociais. Ao conceber o poder como algo que se exerce, que se coloca em jogo, ao invés de ser algo que se possui, Foucault consegue dar conta das relações de poder e também do modo como os sujeitos se constituem por meio dessas relações.

$\mathrm{Na}$ verdade, os conceitos pós-estruturalistas em que se apoiam as ideias de Scott são os elaborados por Michel Foucault e Jacques Derrida. Embasada pela teoria da desconstrução, Scott afirma que é preciso desconstruir o caráter permanente da oposição binária - masculino e feminino. Sua posição é de que o pensamento dicotômico sobre os gêneros que, geralmente, concebe mulheres e homens como opostos e como categorias que se relacionam no interior de uma lógica invariável de dominação-submissão precisa ser rompido (LOURO, 1999, p. 30-31). Pode-se dizer que em Scott o gênero é uma categoria vinculada às relações sociais, ao poder e aos discursos, em cuja base está a teoria foucaultiana dos saberes e do poder. Em Foucault, os saberes são produzidos e compartilhados por meio de determinados tipos de discursos, incluindo os científicos e os relatos literários da vida cotidiana (LLANOS, 2006).

A noção de gênero de Lauretis (1994) também se fundamenta na teoria foucaultiana, apresentando uma compreensão de gênero e de sujeito que, apesar de suas especificidades, assemelha-se muito com as concepções de Scott. Lauretis afirma ser necessário um conceito de gênero que não esteja tão preso à diferença sexual a ponto de essencializá-la, mas que inclua essa diferença como um efeito da linguagem ${ }^{7}$,

${ }^{7} \mathrm{~A}$ linguagem ocupa um lugar central na teoria pós-estruturalista: é vista não apenas como mero veículo de expressão de significados, mas também como algo com poder de construir significados. Nesse sentido, Michele Barret (1999, p. 111) aponta a importância do conceito de discurso de Foucault para pensar sobre os significados produzidos pelos regimes discursivos. contida nas representações sociais. Ela define a construção do gênero como $o$ produto e processo tanto de representação quanto da autorrepresentação (LAURETIS, 1994, p. 217). O seu conceito envolve quatro proposições: a) o gênero é uma representação - que pode trazer implicações concretas tanto sociais quanto subjetivas na vida das pessoas; b) a representação do gênero é a sua construção - que se encontra registrada na arte e na cultura erudita ocidental; c) a construção do gênero efetua-se da mesma forma que no passado - hoje ocorre via academia, práticas artísticas, discursos radicais e até mesmo por meio do feminismo; e d) a construção de gênero se acontece também pela sua desconstrução.

Em Lauretis (2000), as representações de gênero são produtos de diferentes tecnologias sociais, tais como o cinema e os discursos, nos quais se inserem as teorias epistemológicas e as práticas institucionais, bem como as práticas cotidianas - marginais aos discursos hegemônicos - situadas nas microrrelações políticas. Tais tecnologias têm o poder de controlar o campo do significado social e, portanto, de produzir, promover e "implantar" determinada representação de gênero. Porém, existem ainda as condições para uma construção de gênero diversa, "nas margens dos discursos hegemônicos, inscritas nas práticas micropolíticas $\mathrm{e}$ que podem ter um papel importante na construção de gênero, incidindo, sobretudo, no nível das resistências 'locais', na subjetividade e na autorrepresentação" (LAURETIS, 2000, p. 54). Na concepção da autora, a narrativa que envolve a experiência é também uma tecnologia de gênero, por meio da qual se constrói a subjetividade ${ }^{8}$. A expe-

\footnotetext{
${ }^{8}$ Pode-se relacionar a tecnologia da narrativa com a tecnologia de si mesmo, citada por Foucault no seu tratado intitulado "Tecnologias do eu". As técnicas de si permitem ao sujeito realizar operações sobre si mesmo, seu corpo, seus pensamentos e seu modo de ser. De acordo com Foucaul (1994), essa técnica era definida pelos estoicos como askêsis, que longe de indicar renúncia sobre si mesmo, significava a maestria de si na busca da verdade. Par o autor, a askêsis era o conjunto de práticas pelas quais o indivíduo pode obter e assimilar a verdade, e transformá-la em um projeto de ação permanente.
} 
riência é, assim, compreendida como um "complexo de efeitos, hábitos, disposições, associações e percepções significantes que resultam da interação semiótica do eu com o mundo exterior" (LAURETIS, 1994, p. 228). Com isso, autora concebe que, na dinamicidade da própria cultura, o sujeito refaz constantemente a sua experiência mediante seu engajamento com a realidade social; realidade esta que inclui também as relações de gênero. É nisso que resulta a compreensão de gênero como produto não só das representações, mas também da autorrepresentação. Desse modo, tal conceito evidencia que o sujeito, além de sofrer influência das representações sociais discursivas, constrói-se a partir de sua experiência e da produção de novas narrativas dentro de um processo de interação social.

Para Lauretis, o gênero não existe a priori como propriedade do corpo, mas como um conjunto de efeitos que são produzidos nos corpos pelas diferentes tecnologias. Com isso, ela se aproxima da noção de gênero de Judith Butler, que será apresentada mais adiante.

Nota-se que existe uma aproximação nas elaborações teóricas de Scott (1990) e de Lauretis (1994). Ambas concebem que gênero é uma construção que envolve representações simbólicas, práticas institucionais e discursos normativos ou acadêmicos e defendem a possibilidade da desconstrução dos significados de gênero, produzidos por narrativas discursivas que privilegiavam o masculino ${ }^{9}$. Assim como Guacira Louro (1999), essas autoras levam em conta o dinamismo histórico da sociedade. Esse dinamismo supõe que os discursos e as representações que constroem as relações de gênero passam por processos de mudanças que se inscrevem nos discursos construídos reflexivamente por outros sujeitos e em "outro lugar" e que, portanto, as identidades de gênero

${ }^{9}$ Segundo Heretier (1996, p. 2008), todas as sociedades possuem um discurso ideológico e um corpo de pensamento simbólico que historicamente justificam a supremacia masculina; discurso este que é construído sobre um sistema de categorias binárias. também estão sempre se reconstituindo em conexão com essas mudanças sociais e com os novos discursos. Nessa perspectiva teórica, é possível afirmar que a reconstituição das identidades não resulta somente dos novos significados discursivos, mas também de uma autorrepresentação que passa por narrativas reflexivas do próprio sujeito no seu processo de interação social.

Na década 1990, as discussões em torno do conceito de gênero incorporam outros aspectos, como a posição de sujeito, a heteronormatividade, as identidades sexuais marginais e a corporalidade. Abrem-se, assim, novas possibilidades para a compreensão do corpo, não como uma estrutura fixa dada previamente pela natureza, sobre a qual se constrói culturalmente a distinção de gênero, mas como algo que é materializado pela cultura. Nesse sentido, a contribuição de Judith Butler ${ }^{10}$ é significativa, pois ela concebe que tanto o gênero quantoo "sexo" são construídos pelos discursos culturais em contextos determinados, como Foucault já havia evidenciado em a História da sexualidade I (1999b) $)^{11}$.

O gênero não está para a cultura como o sexo para a natureza; ele também é um meio discursivo/cultural pelo qual a 'natureza sexuada' ou o 'sexo natural' é produzido e estabelecido como 'pré-discursivo', anterior à cultura, como uma superfície politicamente neutra sobre a qual a cultura age. [...] Essa produção do sexo como pré-discursivo deve ser compreendida como efeito do aparato de construção cultural que designamos por gênero (BUTLER, 2003, p. 25).

Butler estabelece uma crítica à noção de gênero definida como signifi-

\footnotetext{
${ }^{10}$ Convém mencionar que muitos conceitos da teoria de Butler receberam críticas, inclusive de feministas. Entretanto, Soley-Beltran (2009) retoma as críticas feitas à Butler, mostrando, concretamente, que muitas não se sustentam porque resultam de uma leitura superficial e insuficiente da teoria de Butler.

${ }^{11}$ Nessa mesma perspectiva, é possível remeter ao estudo de Thomas Laqueur (2001) no qual ele examina várias teorias sobre o sexo, criada desde os gregos até nossos dias, mostrando como diversas questões políticas e culturais, que se relacionaram à "natureza da mulher", construíram distintas teorias biológicas sobre a sexualidade.
} 
cados inscritos nos corpos anatômicos diferenciados, como se esses corpos fossem recipientes passivos de significados culturais. Para ela, "o corpo é em si mesmo uma construção e, por isso, não se pode dizer que os corpos tenham uma existência significável anterior a marca do seu gênero" (BUTLER, 2003, p. 25). Assim, o gênero é compreendido como resultado de um processo mediante o qual se recebe os significados culturais, mas que também pode inová -los (LAMAS, 2002).

Em Corpos que pesam (2007) ${ }^{12}$, Butler articula a performatividade de gênero com a materialidade do corpo, reafirmando que, assim como o gênero, o sexo não é uma condição estática do corpo, mas um constructo social. Longe de ser apenas um simples fato biológico, o sexo é um efeito dissimulado do poder e de normas heterossexuais. Autora vê o corpo como produto de um processo, pelo qual as normas regulatórias materializam o "sexo". Essa materialização é a performatividade das normas que se completa por uma reiteração ou por um processo contínuo e ritualizado de citação, que faz com que os indivíduos se conformem aos mandatos culturais. Por isso insiste que

a performatividade precisa ser entendida como a prática reiterativa e citacional, pela qual o discurso produz os efeitos que ele nomeia, ou seja, as normas regulatórias do sexo trabalham de forma performativa para construir a materialidade dos corpos e, mais especificamente, para materializar o sexo do corpo, para materializar a diferença sexual a serviço da consolidação do imperativo heterossexual (BUTLER, 2007, p. 154).

Nesse sentido, a performatividade de gênero refere-se à capacidade performativa ou realizativa da linguagem que permite ao sujeito construir uma identi-

${ }^{12}$ Nessa obra, ela responde às críticas da leitura equivocada do uso da noção de performance que se encontra em seu livro Problemas de gênero e reafirma que a sua compreensão de performativo vem da teoria dos atos da fala, na perspectiva abordada pelos filósofos Austin e Derrida. dade de gênero (ou qualquer outro tipo de identidade). Em Butler, a performatividade remete, também, à realização ou à execução de atos gestuais, de movimentos e posturas físicas de certos registros de estilos e dinâmicas corporais ligados às concepções culturais de feminilidade e masculinidade (LLANOS, 2010).

$O$ conceito de performatividade utilizado por Butler vem da teoria do filósofo John Langshaw Austin (1975), para o qual a linguagem produz realidade. Segundo este autor, "cada vez que falamos fazemos coisas", ou seja, produzimos mudanças no mundo que nos circunda, realizando atos como afirmar, prometer, negar, advertir e ameaçar. O próprio ato de dar nome a uma pessoa é um ato performativo. Se um ato de fala não cria realidade, ele já se encontra na realidade. Para Austin, a performatividade sempre ocorre dentro de um contexto, porque o discurso é inseparável do contexto social. No entanto, enquanto que em Austin $o$ ato performativo de nomear e produzir um efeito decorre da intenção do discurso, em Butler esse ato se aproxima à noção de Derrida, já que, para esta, o poder de produzir materialidade não está na intenção, mas na reiteração do discurso e das novas possibilidades que o poder discursivo pode gerar no processo de interação social ${ }^{13}$. É nessa perspectiva que o conceito de performatividade, que ocorre por meio da linguagem, permite pensar os processos de construção das subjetividades generizadas.

Como mencionado, Butler entende a performatividade como "uma repetição e um ritual", isto é, como uma série de atos que se sucedem no tempo e naturalizam uma determinada forma cultural de ver o corpo sexuado. Desse modo, o gênero não aparece como uma ${ }^{13}$ Butler (2004), em Lenguaje, poder y identidad, relata que tanto Bourdieu como Derrida leem Austin; no entanto, cada um o interpreta de modo distinto. Enquanto que em Bourdieu a força da enunciação performativa está naquele que tem poder legitimado, em Derrida a forç do performativo provém de sua ruptura com um contexto prévio e de

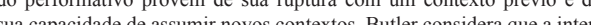
sua capacidade de ass pretaça de Demida ofrece una forna de pense a perfomntividade na relação com a transformação, com a ruptura relativa a contextos prévio e com a possibilidade de inaugurar novos contextos futuros. Entretanto, para ela nenhuma das duas propostas consegue responder ao que constitui a "força" do performativo, mesmo que tomadas em conjunto, pois apontam para uma interatividade social do ato da fala. 
escolha pessoal, mas como uma ação performativa, que se refere a "uma série de ações socialmente definidas, neste caso o gênero, que performa ou constitui certa realidade que aparece como um fato dado, isto é a categoria de "sexo", (SOLEY-BELTRAN, 2009, p. 133, tradução nossa). No pensamento de Butler, a performatividade de gênero não pode ser teorizada sem levar em conta a prática forçosa e reiterativa dos regimes sexuais regulatórios, ou seja, as normas sociais de comportamento inscritas para os diferentes sexos, que fazem com que estes pareçam resultar de uma essência interior. Para Butler,

O gênero não expressa uma essência interior de quem somos, mas é constituído por um ritualizado jogo de práticas que produzem o efeito de uma essência interior. Eu também penso que o gênero é vivido como uma interpretação, ou um jogo de interpretações do corpo, que não é restrita a dois, e isso, finalmente, é uma mutável e histórica instituição social (BUTLER, 2006, p. 4).

A autora desvela como o gênero é performaticamente produzido por práticas regularizadoras de coerência com o sistema da matriz heterossexual ${ }^{14}$. Nesse sistema, os gêneros "inteligíveis" ou aceitos socialmente são os que, de certa maneira, instituem e mantêm as relações de coerência e continuidade entre sexo, gênero, prática sexual e desejo (BUTLER, 2003, p. 38). Nessa lógica, certos tipos de "identidades" não podem "existir". Entretanto, Butler questiona a compreensão das identidades de gênero como resultado de uma coerência normativa entre sexo, gênero e desejo e mostra que a matriz cultural da inteligibilidade de gênero acaba excluindo outras possibilidades de "identidades". Na sua concepção, a performatividade, tomada como uma prática

${ }^{14}$ Butler usa o termo matriz heterossexual para significar a grade de inteligibilidade cultural por meio da qual os corpos, gêneros e desejos são naturalizados e conformados para serem aceitos dentro de uma determinada sociedade. interativa e citacional, em contextos relacionais específicos, por meio da qual os discursos produzem os efeitos que nomeiam está, assim como a inteligibilidade de gênero, sujeita a mudanças de significados culturais, motivo pelo qual não existe uma identidade de gênero estável ou fixa. Sempre há a possibilidade de novos significados, uma vez que os atos repetitivos podem ocorrer de forma descontínua e contingente com sua base normativa (BUTLER, 2003, p. 201). É nessas relações arbitrárias que se situam as possibilidades de transformação do gênero, o que significa que os atributos de gênero não são expressivos, mas performativos. Assim, para Butler, a subversão ${ }^{15}$ reside nas possibilidades culturais que estão excluídas. "É o marginalizado, o abjeto, aquele que não tem uma identidade reconhecida que favorece a possibilidade de subversão" (SOLEY-BELTRAN, 2009, p. 56, tradução nossa). Dito em outras palavras, é por meio da transgressão às normas vigentes, as quais excluem as possibilidades do sujeito, que se torna viável a emergência de práticas inovadoras que, por sua vez, dão lugar às mudanças socioculturais. "Essas práticas inovadoras podem, eventualmente, normalizar-se como novas formas discursivas, ou modificações, que renovam as práticas sociais e culturais" (FEMENÍAS, 2000, p. 182, tradução nossa).

Com a noção de corpos abjetos, excluídos dos princípios de inteligibilidade sem legitimidade e existência normativa diante dos códigos convencionais de gênero, Butler trouxe uma contribuição importante para a teoria queer $^{16}$, com alcance analítico nos estudos recentes relacionados ao corpo e à diversidade de sexualidades. Entretanto, segundo Irene Costera Meijer e Baukje Prins (1998), o abjeto da teoria de

${ }^{15}$ A nocão de subversão de Butler é inspirada na ideia de práticas inovadoras da filósofa francesa Júlia Kristeva (FEMENÍAS, 2000).

${ }^{16}$ Para Louro (2008, p 143), a expressão queer indica o espaço da diferença que não quer ser integrada; uma diferença constituída por sujeito que se colocam contra a normatização evidente na sociedade em geral. Mais do que uma nova posição de sujeito ou um lugar social estabelecido, queer indica um movimento, uma inclinação e, mais de que uma identidade, queer sinaliza uma disposição, um modo de ser e de viver. 
Butler não pode ser restringido ao sexo e à heteronormatividade; ele pode vincular-se a toda classe de corpos cujas vidas não são consideradas "vidas" e cuja materialidade é entendida como uma não matéria, o que permite estudar os sujeitos que são excluídos de diversos espaços sociais por não se adequarem a normas ou princípios hegemônicos.

$\mathrm{Na}$ perspectiva da produção de corpos e sujeitos não inteligíveis às convenções sociais, Butler (2004) analisa a noção de performatividade no sentido do habitus de Bourdieu. Menciona que sua contribuição é importante porque este sociólogo considera tanto o aspecto social como o psíquico para explicar os processos de incorporação das normas sociais, as quais se autorreferenciam nas práticas sociais e na produção dos corpos. Entretanto, Butler aponta os limites dessa teoria, quando esta não consegue explicar o que acontece com os sujeitos que excedem a norma. Isso ocorre porque, em Bourdieu, o habitus refere-se aos rituais cotidianos incorporados por meio dos quais uma determinada cultura se produz e mantém a crença em sua própria "evidência". Nesse processo, ele dá lugar ao corpo nos seus gestos, no seu estilo e no seu "conhecimento" inconsciente como lugar da reconstituição de um sentido prático sem o qual não poderia se constituir como tal. Na opinião de Butler, o corpo não é só o lugar da história incorporada, mas também o instrumento por meio do qual se recuperam as crenças na "evidência" contemporânea.

Em Bourdieu, o habitus forma-se ao longo do tempo, consolidando-se em uma crença mais forte na "realidade" do âmbito social no qual opera. Com isso, este autor considera as convenções sociais como algo que anima os corpos, nos quais, por sua vez,produzem-se e ritualizam-se tais condições como práticas. Assim, a compreensão de que o habitus se forma e se apresenta como formativo leva Butler a afirmar que o habitus corpóreo aparece como uma forma tácita de performatividade, isto é, uma corrente situacional vivida em que se crê ao nível do corpo (BUTLER, 2004).

Contudo, para Butler, o corpo não é simplesmente a sedimentação da ação discursiva por meio da qual ele se constitui. Isso ocorre porque, quando essa constituição fracassa, uma resistência une-se à interpelação no momento em que esta exerce a sua demanda. Assim, algo excede a interpelação, e esse excesso é vivido fora do que é inteligível socialmente, que se visualiza na forma como o corpo excede ao discurso normativo. Esse excesso é o que Bourdieu parece esquecer, já que ignora a incongruência do corpo discursivo e o modo como este excede a sua interpelação. $\mathrm{Na}$ visão butleriana, nenhum ato do discurso pode controlar ou determinar completamente os seus efeitos retóricos. $\mathrm{O}$ fato de que a ação discursiva seja uma ação corporal não significa que o corpo está totalmente presente em seu discurso ${ }^{17}$.

A teoria de Bourdieu pressupõe que o corpo se constitui pela repetição e acumulação de normas e que esta formação seja efetiva. Aquilo que irrompe no curso da interpelação, abrindo a possibilidade de um descarrilamento a partir de dentro, permanece desconhecido. Para Butler, os corpos são formados por normas sociais, podendo haver o risco de, durante o processo de formação, esses corpos não se adequarem ao discurso normativo. Bourdieu, no entanto, não aborda a situação de contingência limitada que rege a formação discursiva do corpo e de suas reproduções. Esta omissão tem consequências na explicação da condição e da possibilidade da agência discursiva. "Ao afirmar que os enunciados performativos só são efetivos quando pronunciados por aqueles que já estão numa posição de poder social para executar as palavras como fatos, Bourdieu elimina a possibilidade de uma agência que surge das margens do poder" (BUTLER, 2004, p. 251, tradução nossa). Para Butler, Bourdieu parece ${ }^{17}$ Nessa análise, Butler toma como principal referência à obra Linguagem e poder de Bourdieu. 
mais interessado em dar uma explicação formal e social da "força" performativa por meio de uma visão de poder social que fica estruturalmente vinculada ao status quo, ao poder legitimado.

Ainda que Bourdieu explique claramente que não são todos os atos performativos que "funcionam" e que nem todos os falantes podem participar da aparente e divina autorização por meio da qual o performativo exerce a sua "magia social" e obriga ao reconhecimento coletivo do poder de autoridade, ele não é capaz de explicar como as posições sociais são construídas por meio de uma operação mais implícita de performatividade (BUTLER, 2004).

Na visão de antropóloga Marta Lamas (2002), quando Butler pensa o gênero como algo que se faz, como uma espécie de estilo corporal, cuja noção se aproxima da noção de habitus, significa que ela compartilha de certas concepções de Mauss e de Bourdieu. Entretanto, a sua teoria possui um alcance maior, porque ela retoma de maneira inteligente a reflexão de Mauss sobre o corpo e a relança. Muito do impacto do seu trabalho se deve a sua reformulação do conceito de habitus, entendido por Butler como um estilo corporal arraigado profundamente em scripts culturais, previamente existentes (LAMAS, 2002).

Sem dúvida, a teoria performativa de Butler, em termos de sexo e gênero, permite pensar outras possibilidades de subjetivação que se processam pela resistência às convenções normativas e culturais. Ela traz para dentro da discussão feminista outros conteúdos que ampliam as possibilidades de análise dos estudos de gênero, até porque seu conceito de gênero como performatividade não contradiz as concepções de Scott e de Lauretis, mas acrescenta outras possibilidades para pensar a construção das subjetividades de gênero. Butler também se insere no feminismo pós-estruturalista ao inspirar-se nas teorias de Derrida e Foucault, uma vez que, para ela, o gênero é uma construção do poder, presente nos discursos normativos e nas práticas sociais. E, como produto do poder, "o gênero não é inseparável do contexto cultural, histórico e político que o produz, mas também intersecciona com outras categorias de classificações identitárias, tais como raça, classe, etnia e sexualidade" (SOLEY-BELTRAN, 2009, p. 38, tradução nossa).

As abordagens feministas pós -estruturalistas afastam-se das vertentes que concebem o corpo como uma entidade biológica e universal: entendem o corpo como um constructo sociocultural e linguístico, produto e efeito do poder. Mesmo havendo acordos e desacordos, as contribuições da teoria pós-estruturalista têm sido um assunto constante nos debates entre as feministas, pois contribui para a crítica ao universalismo, ao essencialismo, ao binarismo e ao racionalismo iluminista (MARIANO, 2005). Assim, o conceito de gênero ancorado no pós-estruturalismo, diferente de outras abordagens, que se focam na análise das distinções de papéis e funções entre mulheres e homens, considera que as próprias instituições, os símbolos, as normas, o conhecimento, as leis e as políticas de uma sociedade são constituídas e atravessadas por representações e por pressupostos de feminino e de masculino e, ao mesmo tempo, produzem e ressignificam essas representações.

Desse modo, quando nos referimos às relações de gênero, estamos sempre pensando nas relações de maneira mais ampla e não somente naquilo que diz respeito aos sujeitos de um determinado espaço institucional: referimo-nos a "todos os discursos e práticas sociais, nas quais se criam as hierarquias e se produzem uma subordinação entre os gêneros, ainda quando trate de uma subordinação simbólica ou da ausência de pessoas concretas, que estão sendo dominadas ou tratadas como subalternas" (LLANOS, 2006, p. 83, tradução nossa). Assim, a expressão "relações de gênero" faz referência às relações de poder fundadas na assimetria cultural entre mulheres e homens. 
Enfim, como bem lembra Norma Blazquez Graf (2011), a perspectiva de gênero no âmbito acadêmico tem surgido como uma ferramenta teórica e metodológica que permite fazer uma crítica às áreas tradicionais do conhecimento, mostrando a necessidade de maior profundidade no exame dos conceitos e pressupostos que orientam a construção do saber. Nesse sentido, a seguir, de forma breve, pontuamos alguns aspectos sobre a legitimidade e importância da categoria de gênero nos processos de produção do conhecimento.

\section{A categoria de gênero na produção do conhecimento}

Uma das grandes contribuições dos estudos de gênero e do feminismo foi a introdução de um modo diferente de fazer ciência, na qual a experiência e a posição do sujeito em seu contexto se constituem como elementos significativos. "Os estudos de gênero e as indagações sobre as epistemologias feministas introduziram, ao lado dos outros estilos de fazer ciência social, um estilo que deu mais lugar à reflexão sobre a subjetividade do/a autor/a e da construção das subjetividades dos sujeitos sociais" (MACHADO, 1998, p. 125). Assim, sem deslocar o estilo mais objetivo de uma escrita sem sujeito ou do "nós", produziu-se outra forma de escrever ciência em que o sujeito se coloca e assume sua construção científica. Esse novo estilo dá voz à subjetividade reflexiva do sujeito social e, sem dúvida, tem sido uma das contribuições do feminismo.

$\mathrm{Na}$ trajetória dos estudos feministas, o conceito de gênero foi assumindo diversos desdobramentos que não desconsideram as perspectivas anteriores, mas ampliam as possibilidades analíticas nas formas de abordar os objetos de pesquisa. Pode-se afirmar que o conceito de gênero passou a ser utilizado de forma generalizada em diferentes áreas do saber e se consolidou como uma nova metodologia de análise social. De acordo com Lia Machado (1998, p.108),

\begin{abstract}
a generalização do uso do conceito de gênero no campo intelectual, na área da sociologia, literatura, filosofia, psicanálise, antropologia, história e psicologia, ocorrida nos anos de 1980 e 1990, trouxe consigo o compartilhamento da radicalização da ideia da desnaturalização das categorias de homem e de mulher e da radicalização da construção simbólica das noções de feminino e masculino.
\end{abstract}

Para essa autora, é possível falar da construção de um novo paradigma metodológico pelas análises de gênero. Sua afirmação fundamenta-se em três razões: a existência de uma afirmação compartilhada sobre a ruptura entre a noção biológica de sexo e a noção social de gênero; o privilégio metodológico das relações de gênero sobre outras categorias, como a de mulher e homem; e a afirmação da transversalidade de gênero nas diferentes áreas sociais. $\mathrm{O}$ conceito de gênero permitiu também, sexualizar as experiências humanas, fazendo com que as mulheres percebessem que o sexo, mesmo sendo concebido como parte constitutiva das experiências, raramente era incorporado como uma dimensão analítica (RAGO, 1998).

Um dos grandes aportes teóricos do feminismo é mostrar que a experiência é sexualizada e interfere diretamente na produção do conhecimento. Diante disso, os estudos feministas propõem uma epistemologia alternativa, que atribui novos sentidos para aquilo que se considera conhecimento, permitindo, com isso, a ressignificação da objetividade e de outras categorias centrais para a filosofia feminista e para as ciências sociais, como é o caso da experiência $(\mathrm{BACH}, 2010)$. Tal fato reafirma a importância da análise de gênero nos processos de produção do conhecimento.

Pode-se afirmar que, em face à insuficiência de teorias existentes que 
explicassem a permanência da desigualdade entre homens e mulheres, a categoria de gênero reivindicou um lugar específico no campo intelectual e vem dialogando com outras categorias. $\mathrm{O}$ gênero como categoria analítica leva em conta as relações e por isso enfatiza que a construção do masculino e do feminino se define na relação e se constitui socialmente, culturalmente e historicamente em contextos diferenciados, envolvendo tempos, espaços e culturas específicas.

É na área das ciências humanas contemporâneas que a categoria gênero encontrou um campo favorável, desnaturalizando as identidades sexuais e postulando a dimensão relacional. $\mathrm{O}$ gênero constitui-se em um conceito de caráter interdisciplinar que abrange diversas áreas acadêmicas e vem contribuindo eficazmente no campo intelectual das Ciências Sociais, as quais têm como centro de interesse as relações sociais que se estabelecem entre os indivíduos e a estrutura social. Segundo Mariano (2008), o gênero, como categoria de análise, tem para o feminismo um valor equivalente ao de categoria de classe para o marxismo. Desse modo, o gênero é uma ferramenta conceitual que permite compreender como se produzem, em nossa sociedade, as relações de exploração, de dominação e de violência, bem como as hierarquias desiguais de gênero.

Gênero, como categoria analítica elaborada nos estudos feministas, tem a função de colocar luz sobre as diferentes posições ocupadas por homens e mulheres nos diversos espaços sociais, dando destaque ao modo como as diferenças construídas socialmente resultam em critérios de distribuição de poder, portanto, em como se constroem as relações de subordinação (MARIANO, 2008, p. 355).

Na visão de Mariano (2008), o conceito de gênero é central para entender as construções e as classificações dos sistemas de diferença, de modo que a produção das identidades de gênero pode ser compreendida como parte de um sistema de relações sociais, simbólicas e psíquicas, no qual homens e mulheres são diferentemente alocados.

A partir da década de 1990, os estudos de gênero ampliaram-se tanto em termos temáticos quanto de abordagens: diversificaram-se criativamente as fontes de pesquisa, aprimoraram-se as estratégias de investigação e priorizaram-se outros temas como a questão da violência, dos direitos reprodutivos, do corpo e do imaginário feminino (MATOS, 2003). Tudo isso aponta para os grandes alcances da categoria analítica de gênero e sua contribuição para diferentes áreas acadêmicas, mesmo que em muitas dessas áreas essa categoria seja considerada, ainda, marginal ou de "menor valor". Na avaliação de Llanos (2010, p. 41), o uso da categoria de gênero e dos estudos feministas como ferramentas analíticas não só enriquecerá as Ciências Sociais, como também aumentará as possibilidades de eliminar a hierarquia entre os sexos, contribuindo, assim, com a construção de uma sociedade mais justa e equitativa.

\section{Considerações finais: os usos de gê- nero na produção do conhecimento}

A reflexão deste ensaio teórico não deixa dúvidas sobre a legitimidade do conceito de gênero como categoria analítica, tanto para os processos de produção do conhecimento quanto para a compreensão das relações sociais em suas diferentes dimensões, sobretudo no que se refere às desigualdades de gênero, às hierarquias de poder, à invisibilidade social das mulheres e de outras identidades sexuais marginais, às estratégias de resistência dos sujeitos "subalternos" em seus processos emancipatórios, às políticas de reconhecimento e aos processos de produção de determinados modelos de subjetividades masculinas e femininas nas mais distintas esferas da sociedade. Convém 
afirmar que os distintos desdobramentos históricos desse conceito têm permitido maiores alcances nos processos analíticos, mesmo que muitas vezes tais processos parecem um tanto complexos e contraditórios.

Poder-se-ia perguntar, então, se o gênero, como categoria social e analítica, é também uma perspectiva metodológica. É de nosso conhecimento que uma metodologia inclui procedimentos técnicos, modelos teóricos e organização de um determinado estudo de acordo com a hipótese que orienta e perpassa o todo do trabalho acadêmico. Qualquer investigação que assume uma abordagem qualitativa, em geral, tem dado destaque ao sujeito mais do que aos dados puramente materializados. Portanto, uma metodologia qualitativa com perspectiva de gênero coloca no centro o sujeito, mas um sujeito que não é neutro, abstrato ou universal. Trata-se de um sujeito situado, que possui também uma posição de gênero, que se cruza com outras categorias como classe, raça/etnia, cultura e geração.

Entretanto, convém lembrar que o sujeito será compreendido de acordo com a abordagem teórica de cada estudo. Na perspectiva do feminismo marxista, por exemplo, o sujeito pode ser compreendido como generizado ${ }^{18}$ oprimido, enquanto que na perspectiva de Gramsci o sujeito pode ser visto como subalterno e hegemônico. Nos estudos feministas, os vetores que diferenciam a forma de compreensão do sujeito são as vertentes de sexo e gênero.

Atualmente, existem muitos estudos que se caracterizam "com perspectiva de gênero" e que não se fundamentam, necessariamente, nas teorias feministas. Contudo, tais estudos, de alguma forma, têm problematizado as dinâmicas sociais e as relações de poder produtoras de desigualdades, propondo 18 O termo "generizado" é usado no sentido que esboça a feminista Londa Schienbinger (2001, p. 145) para referir-se "aos comportamentos, interesses, ou valores culturais tipicamente masculinos ou femininos, cujas características não são concebidas inatas e nem arbitrárias, mas como realidades construídas por circunstâncias históricas que, por isso mesmo, podem mudar por outras circunstâncias históricas". a construção de políticas públicas para a redução dessas desigualdades. Há, também, estudos, projetos e relatórios que assumem a perspectiva de gênero sem colocar em cena a dimensão do poder e as dinâmicas socioculturais que produzem as desigualdades sociais, cujo interesse é o de angariar recursos financeiros de agências para garantir práticas funcionais ou até para a produção de políticas voltadas para as mulheres. Em geral, esses estudos usam o gênero somente em uma perspectiva descritiva a fim de analisar ou de distinguir a situação diferenciada de homens e mulheres em um determinado espaço social. Tais estudos se vinculam às convenções sociais e, não raro, colocam o gênero como igual ao sexo, sem problematizar sob o ponto de vista das abordagens teóricas do feminismo. Outros estudos se caracterizam como não sexistas para sinalizar uma perspectiva não androcêntrica, de modo que a perspectiva de gênero aparece mais como um corretivo no sentido de visibilizar as mulheres nos processos sociais e acadêmicos. Porém, há uma grande leva de estudos de gênero em que a teoria feminista é vista como uma ferramenta útil que permite evidenciar o modo como se produzem as desigualdades de gênero. Esses estudos têm desnaturalizado práticas e papéis sociais de gênero, mostrando como o poder dos discursos, produzidos somente pela perspectiva do sujeito masculino, tem exercido influência na produção das subjetividades femininas e masculinas. Argumentam, ainda, que as identidades e práticas sociais de gênero, sendo resultado de uma construção histórico-cultural, também são passíveis de desconstrução e de ressignificação, já que não existem identidades fixas. Podese afirmar que são os estudos de gênero fundamentados na teoria feminista que mais parecem desvelar os processos que constroem as desigualdades sociais de gênero e as possibilidades de subversão das convenções culturais de gênero.

Nesse sentido, como cientistas sociais e sujeitos do conhecimento tor- 
na-se inviável tomar o conceito de gênero de maneira ingênua, reduzindo-o a estudos de mulheres e muito menos a uma variável de distinção de sexo. $\mathrm{O}$ conceito de gênero tem a ver com relações de poder e com a construção sociocultural do masculino e do feminino, que ocorrem por meio de dinâmicas culturais inscritas em discursos, representações simbólicas e práticas sociais.

Pensar e produzir saber desde a perspectiva de gênero implica entrar em um campo amplo, complexo e com uma longa trajetória, que foi sendo construída no universo acadêmico. Nesse sentido, hoje não se discute mais a importância da categoria analítica de gênero, porque ela já se constituiu em uma ferramenta teórica relevante, sobretudo no campo das Ciências Sociais, e a sua utilização permite um olhar atento para os núcleos geradores de desigualdades entre homens e mulheres, bem como nas relações intragênero. Essa perspectiva analítica tem gerado outra forma de produzir conhecimento, possibilitando desvelar os conteúdos sexistas que podem estar nos imaginários, nas representações simbólicas, nos discursos e nas práticas sociais, de modo que as análises de gênero aparecem como parte de um novo paradigma metodológico e epistemológico.

Nesse sentido, uma das grandes contribuições dos estudos feministas e de gênero é mostrar a importância da posição do sujeito que produz o saber, enquanto um sujeito generizado, uma vez que essa posição tem influenciado historicamente a produção do conhecimento científico, ocultando as experiências do universo feminino. Colocam-se, assim, novos sentidos sobre o que se considera conhecimento e se problematiza a pura objetividade e universalidade do saber científico, mostrando que esse saber é sempre situado, parcial e subjetivo, porque nele se inscreve a experiência do sujeito do conhecimento.

Convém mencionar que as correntes do feminismo partem da afir- mação de que o sujeito que conhece é alguém que está inserido em uma determinada situação, posição e circunstância, considerando, com isso, que nenhum conhecimento se produz desde "nenhum lugar". Dessa forma, pode-se dizer que o feminismo se caracteriza como uma postura hermenêutica, cuja perspectiva metodológica considera que cada um de nós é habitante de uma cultura, de uma época, de uma situação geográfica e de uma posição de gênero. $\mathrm{E}$, portanto, é desde essas referências que interpretamos e compreendemos o mundo. Ou seja, olhamos para a realidade e produzimos saberes desde dentro e não a partir de uma neutralidade supra-humana.

A categoria analítica de gênero, que emergiu dentro da teoria feminista, hoje é assumida por diferentes áreas acadêmicas por seu caráter interdisciplinar. Contudo, se constata a sua grande contribuição no campo das Ciências Sociais, que tem como principal foco as relações sociais que se estabelecem entre os indivíduos e a sociedade. Para o feminismo, a categoria de gênero tem um valor equivalente ao da categoria de classe para o marxismo, justamente por permitir a compreensão da forma como as subjetividades masculinas e femininas são constituídas e do modo como as relações de dominação, hierarquização e desigualdade social são produzidas e reproduzidas no interior das sociedades humanas.

Por fim, diante do que foi discutido neste ensaio teórico, consideramos importante que os sujeitos do conhecimento rompam com certos preconceitos em relação aos estudos de gênero e tenham maior sensibilidade quanto à essa questão, pois atualmente é politicamente necessário produzir conhecimento considerando não só o gênero, mas também outros eixos da diferença social, como os de raça, classe, etnia, orientação sexual e cultura. Neste ensaio, demos maior destaque ao gênero e ao seu estatuto nos processos de produção do conhecimento, entendendo que ele tem também 
intersecção com esses outros eixos diferenciadores. Reiteramos a importância de tomar consciência de que é possível construir uma ciência mais crítica, capaz de apontar caminhos para a formação de uma sociedade mais justa, igualitária e equitativa, por meio da utilização do conceito de gênero e da sua valorização como um dos instrumentais teórico-analíticos em estudos e pesquisas científicas, uma vez que todas as relações sociais são atravessadas também por dinâmicas culturais de gênero.

\section{Referências}

1. AUSTIN, J. L. How to do things with words. Cambridge: Havard University Press, 1975.

2. BACH, A. M. Las voces de la experiencia: el viraje de la filosofía feminista. Buenos Aires: Editora Biblos, 2010.

3. BARRET, M. As palavras e as coisas: materialismo e o método na análise feminista contemporânea. Revista Estudos Feministas, Florianópolis, CFH/ UFSC, v.7, n. 1/2, p. 109-126, 1999.

4. BEAUVOIR, S. O segundo sexo: fatos e mitos. (Vol.1). São Paulo: Circulo do Livro, 1949.

5. BUTLER, J. Problemas de gênero: feminismo e subversão da identidade. Rio de Janeiro: Civilização Brasileira, 2003.

$6 . \quad$ Lenguaje, poder y identidad. Madrid: Editorial Sintesis, 2004.

7. Entrevista com Judith Butler: $\mathrm{O}$ gênero é uma instituição social mutável e histórica. Revista IHU on-line, São Leopoldo-RS UNISINOS, n. 199 , p. 3-4, 9 out. 2006. Entrevista concedida ao IHU On-Line. Disponível em: <http://www.unisinos.br/ihuonline/>. Acesso em 22. 01.2009.

8. Corpos que pesam: sobre os limites discursivos do "sexo". In: LOURO, Guacira Lopes (Org.). O corpo educado: pedagogias da sexualidade. 2.ed. Belo Horizonte: Autêntica, 2007. p.151-172.

9. COSTERA MEIJER, I.; PRINS, B. How Bodies come to Matter: an interview with Judith Butler, Signs: Journal of Women in Culture and Society, v. 23, n. 2, p. 275-286, 1998.

10. FEMENÍAS. M. L. Sobre sujeto $\mathbf{y}$ género: lecturas feministas desde Beauvoir a Butler. Buenos Aires: Catálogos, 2000 .

11. FLAX, J. Pós-modernismo e as relações de gênero na Teoria Feminista. In: Hollanda H. (org.) Pós-modernismo e política. Rio de Janeiro: Rocco, 1992. p. 217-250.

12. FOUCAULT, M. As técnicas de si In: WEB - Textos de Foucault em Português. Paris: Gallimard. 1994. Vol. IV, p. 783-813. Disponível em: <http://www. unb.br/fe/tef/filoesco/foucault/biblio. html>. Acesso em 13.11.2008.

13. Microfísica do poder. 14. ed. Rio de Janeiro: Edições Graal, 1999a.

$14 . \quad$ História da sexualidade: a vontade de saber. 13 ed. São Paulo: Edições Graal, 1999b.

15. FRASER, N. Iustitia interrupta. Reflexiones sobre la posición "postsocialista”. Bogotá: Universidad de los Andes/ Siglo del Hombre Editores, 1997.

16. GILLIGAN, C. La moral y la teoría: psicología del desarrollo femenino. México: Fondo de Cultura Económica, 1982.

17. GRAF, N. B. El retorno del las brujas: incorporación, aportaciones y crítica de las mujeres a la ciencia. Ciudad de México, DF: UNAM/CEIICH, 2011.

18. HÉRITIER, F. Masculino feminino: o pensamento da diferença. Lisboa: Instituto Piaget, 1996. 
19. LAMAS, M. Cuerpo: diferencia y género. México: Taurus Pensamiento, 2002.

20. LAQUEUR, T. Inventando o sexo: corpo e gênero dos gregos a Freud. Rio de Janeiro: Relume-Dumará, 2001.

21. LAURETIS, T. A tecnologia de gênero. In: HOLANDA, Eloísa Buarque de (Org.). Tendências e impasses: o feminismo como crítica da cultura. Rio de Janeiro: Rocco, 1994.

22. . La tecnología del género,

In: .Diferencias: Etapas de un camino a través del feminismo. Madrid: horas y Horas La Editorial, 2000, p. 3369.

23. LlanOS, G. C. Sexo, género y feminismos: tres categorías en Pugna. Cali, Colombia: Universidad del Vale, 2006.

24. Decidimos, hacemos, somos: discurso identidades de género y sexualidades. Cali, Colombia: Universidad del Vale, 2010

25. LOURO, G. L. Gênero, sexualidade e educação. 3. ed. Petrópolis: Editora Vozes, 1999.

$26 . \quad$. O "estranhamento" queer. In. STEVENS, Cristina M.T.; SWAIN, Tânia Navarro. A construção dos corpos: perspectivas feministas. Florianópolis: Editora Mulheres, 2008. p.141148.

27. MACHADO, L. Z. Gênero, um novo Paradigma? Cadernos Pagu, Campinas-SP, n.11, p.107-125, 1998.

28. MARIANO, S. A. O sujeito do feminismo e o pós-estruturalismo. Revista de Estudos Feministas, Florianópolis, CFH/UFSC, v.13, n.3, p. 483-506, 2005.

29. Modernidade e crítica da modernidade: a Sociologia e alguns desafios feministas às categorias de análise. Cadernos. Pagu, Campinas-SP, Unicamp. n.30, p. 345-372, jan.-jun.2008.
30. MATOS. M. I. S. Da invisibilidade ao gênero: odisseias do pensamento percurso e possibilidades nas ciências sociais contemporâneas. In: SOTER (org). Gênero e Teologia: Interpelações e perspectivas. São Paulo: Edições Loyola, 2003. p. 67-86.

31. NICHOLSON, L. Interpretando o gênero. Revista de Estudos Feministas, Florianópolis, CFH/CCE, UFSC, v. 8, n.2, p. 9-41, 2000.

32. PIERUCCI, A. F. Ciladas da Diferença. Tempo Social, São Paulo, USP, v. 1, 2 sem., 7-33, 1990.

35. RAGO, M. Descobrindo historicamente o gênero. Cadernos Pagu. Campinas-SP, n.11, p. 89-98, 1998.

36. RUBIN, G. O tráfico de mulheres: notas sobre a "economia política" do sexo. Pernambuco: SOS Corpo, 1993.

37. SANTOS, B. S. de. A crítica da razão indolente. Contra o desperdício da experiência. São Paulo: Cortez, 2000. p, $47-117$.

38. SCHIENBINGER, Londa. O Feminismo mudou a ciência? Bauru - SP: EDUSC, 2001.

39. SCOTT, J. W. Gênero: uma categoria útil de análise histórica. Revista Educação e

Realidade. Porto Alegre: UFRGS, v.16. n.2, p.5-22, 1990.

40. . Igualdade versus diferença: os usos da teoria pós-estruturalista. Debate feminista. Cidadania e feminismo (edição especial) São Paulo: Cia melhoramentos, 1999. p. 203-222.

41. A cidadã paradoxal: as feministas francesas e os direitos do homem. Florianópolis: ed. Mulheres, 2002.

42. SOLEY-BELTRAN, P. Transexualidad y la matriz heterosexual: un estudio crítico de Judith Butler. Barcelona: Ediciones Bellaterra, 2009. 